\title{
Conceptual Grounding of Education as Human Formation - a Dialogue between Aspects of the Field of Education Itself and the Buddhist Tradition
}

\author{
José Policarpo Junior ${ }^{1, *}$, Ferdinand Röhr \\ ${ }^{1}$ Department of Socio-Philosophical Foundations of Education, Universidade Federal de Pernambuco, Recife, 50670-901, Brazil. Email: \\ ${ }^{2}$ Department of Socio-Philosophical Foundations of Education, Universidade Federal de Pernambuco, Recife, 50670-901, Brazil
}

\begin{abstract}
This article demonstrates and takes as its underpinning the idea that education has a normative dimension without which it cannot constitute itself as a specific field of practice and knowledge. This normative aspect of education relates to the need to promote, based on appropriate principles, the humanization of the human being. The article analyzes theoretically the concept of education to demonstrate and to underpin such principles that characterize education as human formation: equality, truth, utility, reasonability, introspection, individuation, freedom. Without these principles, education could hardly be conceived as a proper field of knowledge and practice. Then, the article undertakes a comparative analysis of these formative princip les with those that emerge from the Buddhist tradition with regard to the understanding of human beings and their orientation in the world.
\end{abstract}

Keywords Human Formation, Buddhism, Education, Individuation, Introspection, Equality, Truth, Utility, Reasonability

\section{Introduction}

This article sets out to make a contribution to the conceptual clarification of education as an intrinsic part of human formation by means of theorizing on the very objects of the field of education and making an incursion into the Buddhist tradition as to the spiritual formation of human beings.

The scope of this article may at first seem rash if it is admitted that there possibly is an intrinsic incompatibility between the two traditions or theoretical-practical fields namely, education as it is structured in its systems, knowledge and practices, and the Buddhist tradition, regarded as a broad field of systematizing thinking and practice on human nature and how it is formed. Th is apparent incompatibility is the result of $h$ istorical reasons, which, over the centuries and especially in the process by which the En lightenment secularized Western civilization, prompted the leaking of the concept of education to the extent that this goes back to comprehending human beings and what is appropriate to and suitable for forming them. It is not the objective of this article to deal with such historical reasons, but rather to tackle theoretically the pertinence of throwing light on the conceptual foundations of education by having

* Corresponding author:

jpj@form acaohumana.org (José Policarpo Junior)

Published online at http://journal.sapub.org/edu

Copyright (C 2012 Scientific \& Academic Publishing. All Rights Reserved recourse to its own tradition as a field of knowledge and to the practice and tradition of Buddhism. Therefore, the pertinence of the compatibility between the two traditions, with respect to the problem dealt with in this study, will be demonstrated throughout this article.

As to the need to undertake a conceptual clarification of education, the reasons for doing so are not only theoretical but derive equally from practical issues. Anyone who scrutinizes the educational field, as it is expressed in scientific and academic institutions, will have no great difficulty in perceiving: the diversity of themes and subthemes dealt with; various forms of investigation, which do not share a common and clearly accepted, theoretical and methodological corpus; different privileges granted to other scientific fields, very often without acknowledging the scientific character of the field of education itself; and theories that are dissonant or have little connection with each other. To sum up, such facts lead to the conclusion that there is a phenomenon that might, at the very least, be deemed conceptual imprecision. On the other hand, such an institutional manifestation of a lack of defining boundaries and the intrinsic nature of the educational field also ends up being reflected on all the practices that structure the life of educators whether as university lecturers, school-teachers or in their own acquisition of educational qualifications. Obviously, this article does not set out to resolve the problems mentioned as to the educational field. Nor does it intend to problematize directly the reasons and consequences of the conceptual fragility of this field. However, it is 
assumed here, as a presupposition, that education is theoretically and conceptually fragile as a proper field of study, research and intervention in the pantheon of the sciences.

As to how the article will refer to Buddhism, it has to be borne in mind that there is not only one Buddhist tradition, but several, each of which offers different kinds of teaching, so that Buddhism can be manifested in different ways, depending on the purpose in view. In line with the objective of this article, an effort will be made to present some of the main Buddhist forms of understanding in a way that is intelligib le to the field of education. This p resentation will be conducted based on the works of a limited number of Buddhist masters from various schools and traditions, and will also be grounded on the training undertaken by and the experience of the first of these authors. Although the Buddhist forms of understanding selected for this article, insofar as they are not tethered specifically to the scope and language of only one particular school, may be considered arbitrary by some, the reader can check the pertinence of what is stated here in various other publications, especially as to how Buddhist contributions have been received in the West by way of the concepts of mindfulness and awareness (e.g.:[1],[2],[3],[4]).

Finally, in line with the objective of this article which has already been explained above, the effort made to clarify the concept of education will be initiated by having recourse to the idea of a normative dimension of education elucidated by reflection on some of its fundamental principles, such as: equality, truth, utility, reasonability, introspection, individuation and freedom. The idea of a normative dimension is presented here as an update of the concept of arete that informed and directed the spiritual and civilizing construction of the notion of Paideia, the main idea-engine at the historical roots of the concept of education ([5]). After having done this, the Buddhist contribution to the idea of human formation will be addressed.

\section{Normative Dimension of Education}

In accordance with the preceding introductory terms, one fundamental aspect of education without which it becomes almost impossible to understand the intrinsic nature of what it is to educate is its normative dimension. One cannot even think of education, whether from a theoretical standpoint, or from the practical one, without presupposing that it is based on the assumption that human beings should reach a certain condition that has not yet been developed, been updated or is as yet present. The definition of the nature of the condition to be achieved does not enjoy, however, consensus within the field of education. The assumption that education cannot be conceived, nor exist as a practice, without this normative dimension is, however, a principle, which those who insist on a rigorous scientific approach may resist because they do not consider the principle itself can form part of the scientific character of any field even of the field of education.
Due to reasons of a historical, social, economic and cultural order, a detailed discussion of which would go far beyond the scope of this article, science has, over the centuries, undergone a progressive conversion to the study of what it is, i.e. that it exists independently of the subject and is devoid of any consideration as to what it should be. According to this understanding, scientific reason is that which is able to grasp an objective phenomenon independently of the way in which the subject has access to the phenomenon. There is a need to state, however, that this is a characterization determined by the way that reason affirms itself in the world and in modern culture, although it has not always been like this and nor is such an understanding of reason a total and comprehensive one ([6],[7]). Education, however, perhaps unlike other scientific fields in the humanities and natural sciences, is a field of knowledge and practice which cannot exist without the admission of its normativity. This dimension is therefore something which when expressed consists not only of describing what it is but also requires to include a tendency towards setting out what it should be.

At this point, however, it is important to recognize that some other areas are also based on this intrinsic normativity, as in the case of medicine and psychoanalysis; and besides investigating their very object, they are founded on the understanding that their ultimate goal consists of providing or maintaining people's health and physical well-being and the subject's autonomy and self-deliberation - i.e. they cannot take as their base only that which is, but they must also always consider what it should be. For this reason, Castoriadis[8] once took up Freud's statement of the impossibility of politics, psychoanalys is and pedagogy, since, on considering the sui generis way of how each one is established, it is seen that the three always assume something that is not yet given, namely: a free and self-organized society, a free and self-deliberative subject, and a free and humanly formed person.

Having admitted the normative dimension of education, nothing yet can be said as to its content, i.e. as to that to which its coming into being points. This aspect causes great uneasiness among educators themselves, since there is no simple answer to this. What also contributes to the lack of clarity or conviction as to the normative dimension of education is the fact that different voices outside the educational field consider themselves fully able to advocate what they believe to be the non-transferable task of educating. Since there is no clarity about the importance and nature of that dimension in the field of education itself, it is easy for anyone to announce the educational goal that seems to him/her the most convenient or suitable one. Thus, drawing only on the last thirty or forty years, some of the educational goals the preaching of which have had great influence, especially in Brazil, have been: the production of human capital, revolution or social transformation, skills-giving and educating for democracy, citizenship, the competences and training of the learner-subject. One should not deny the pertinence of any of these objectives, nor even 
their specific relationship with the task of educating. However, there is a need to recognize that all these ends stem from concerns outside education or other fields of knowledge - such as economics, sociology, political science, psychology - but not from education itself.

Thus, to make it possible to visualize the direction in which the normative content of education leans, it is essential to explain and reach an agreement, albeit in general terms, about all that which might come to define its nature and scope.

\section{Elements and Underpinnings of the Normative Dimension of Education: Human Formation}

All human beings emerge into a world that presents itself to them as a vital context that may prove to be receptive or threatening to them. On the other hand, to emerge in this world, humans need the concurrence of a relationship between at least two other people. The mere physical survival of the human being who has recently arrived in this world will depend fundamentally on this first context welco ming him/her in a friendly way, or otherwise. From the recently arrived being, what will be demanded, explicitly or implicitly, are to follow and respect rules, modes of conduct and values regarding the nature of this context that shelters him/her. Thus, in a broad or narrow way, a human being is, from his/her origin, a being that is found to be in relationship to others. To a large extent the quality of his/her life will depend on the form, nature and intensity with which such relationships are imprinted on him/her: human enterprise will necessarily depend on the intensity of approval or disapproval of the inter-relational context into which it is thrust.

However, the capacity to grasp the extent of the network of connections responsible for the existence of the particular being can be wide or restricted. Thus, a person may or may not understand that his/her own survival maintains, in several ways, links to people who practice plant extractivism, for example, in a country that is thousands of miles from the place where they live; these being people with whom they will probably never have any kind of personal relationship. Thus, one individual in particular may or may not have that understanding. As a general rule, however, people believe they have a relationship of dependency only with the personal contacts with whom they can personally identify themselves. Therefore it is not uncommon that the way that the particular subject conceives of himself and the bonds of loyalty that he/she nurtures towards some collective are both defined based on this perception regarding his/her condition of known dependency. Thus, the main rudiments arise of a conception of oneself itself that is structured by such personal relationships and by their mental representation. This is why very young children begin to feel Jewish, Muslim, Palestinian, Brazilian, viz., that they belong to this or that community. Set against this, depending on the manner and scope of how the particular being particularly grasps the web of relationships that keeps him/her alive, may or may not come rivalries and enmities between the ways in which other beings see themselves for themselves in the world.

From what has been said above, the result is that, to a greater or lesser degree, every particular human being necessarily depends on cultivating a certain way of being and living among humans and nature. In other words, every human being needs to cultivate a form of ethics that will be as wide or as restricted as his/her mental representation of the inter-relational woof in which he/she finds himself. This aspect of the human condition is thus clad in an important dimension of normativity in education. In the Delors [9] report, this dimension is deemed to be learning to "live together". Thus, the human condition itself requires such learning, a lthough very often social situations greatly restrict a full coverage of "living together" to, at most, the limits of a village, a family, a class or of some other form of collectivity. In this regard, there is an educational dimension about which there is very often a discrepancy and even an opposition between ideals and social norms, at narrower or broader levels, and educational ideals. This is also one of the obstacles which, beside others which will be defined later, imply the conceptual differentiation between education and socialization, since the contents and goals of them both will not always converge.

According to what has been said so far, education emerges as that guided practice that enables, wherever there is a difference, a fundamental equality of dignity, integrity and rights to be seen. At this point, socialization left to itself will extend this equality only to spatial, historical, social and cultural limits that define a given collective identity, while it will fall to education to broaden that attribute as much as possible to all human beings and the surrounding ecosystem itself. When education is subsumed completely to the dictates of a society or culture, that educational dimension is practically extinguished, which necessarily implies the falsification of its practice and of the very concept of what to educate is about. Since this occurrence is not rare in education, theorizing about educating very often ends up consecrating this subordination of education to social and cultural dictates, thus legitimizing, albeit in conceptual terms, the falsification of the concept and practice of education. This ends up leading to preventing educational practices being viewed as conceived as per their intrinsic meaning and not only according to existing social and cultural determinations. Therefore, the theoretical tendency that considers itself satisfied on demonstrating this way of determining the phenomenon of educating, thus sanctions, on behalf of a pseudo-realism, or of an alleged battle with idealism, the atrophied condition in which education is found in such a context.

Thus, we can say that this first normative dimension of education (the principle of equality which arises from reaching an understanding on how broad the interconnection with innumerable beings and situations is), which will not necessarily always be in contradiction with its existing 
factual dimension, is something belonging to educating and does not derive simply from the knowledge collected in the conceptual fields of sociology, politics, psychology, economics, nor of philosophy.

Associated with this understanding of the broad interdependence between human beings and the princip le of equality that arises from this is the dimension of knowledge and its guiding princip le is the search for truth. This princip le is also related to the condition of human life.

On making a historical and philosophical retrospective review, one can recognize the legitimacy of the claim that reason always nurtured the "project to dispel ignorance and superstition and make men lords"[6]. In other words, reason, as the basic dimension of knowing and thinking, is not expressed initially, or at many other historical points in time, as an end in itself nor as a mere instrument for purposes other than perfecting and emancipating humans. This means that no matter how much reason has been developed and makes itself available in the subjective instances of each particular individual and in the objective manifestations of technological, infrastructural and cultural achievements, it does not achieve its intrinsic objective until and unless such subjective and objective expressions are articulated and placed at the service of the progress and betterment of mankind and of the world that mankind inhabits. The dimension of truth is not disassociated from this understanding.

The assumption of such a principle has implications for understanding the statute of truth to the extent that this also leads to what corresponds to this being a dimension of becoming and not only what is. What Marcuse[10] identified in reason conceived as per the Hegelian dialectic is also valid here, namely, the understanding that truth is found not only at the level of facts, but also points to a state of affairs in which subjective judgment is not divorced from objectivity, but, on the contrary, communes with it in a peaceful relationship. In this case, the reasoning that says what something is, not only expresses a property or temporary and identifiable condition at the present moment, but also marks a conceptual advance of the condition that the object tends to achieve in accordance with its own essence and historical coming into being. For the current discussion, what is of interest is to understand that the search for truth is not limited to asserting what an object or situation may be, regardless of anything else. Without undervaluing this aspect, truth is also the anticipation or the announcement that knowledge derived from all the human capabilities made available in historical, social, cultural and individual ways - finds its fulfillment in the manner it serves human betterment. From what has been set out, therefore, it can be affirmed that not everything that manifests itself as the objectification of cognitive, instrumental and abstract capacities of humankind is in fact true in the strict sense of the term.

The Report of the International Commission on Education for the $21^{\text {st }}$ century[9] states that among the main purposes of education are "learning to know" and "learning to do". In the light of the foregoing reflection, what may be identified as the guiding principles of these two purposes are truth and utility. Although there has been much debate on the conflicting relationship between truth and utility in the history of philosophy, for the purposes of this paper what is important is to stress how both principles crosspenetrate and complement each other. In the strict sense of the idea of truth presented above what stands out is the very characteristic of utility. Given the relations of human beings with each other and with the ecosystem, the truth which manifests itself as a synthesis of what is and what it becomes is also clad with the sense of the utility that serves the purpose of human progress and betterment. According to this understanding, the useful is true and the truth is also that which is useful.

A large part of the conflict between these two principles is based on particularizing the amplitude of one or both of them. Thus, for example, what is configured as very useful in the economic sphere, and which may be true in the existing order of things, does not necessarily meet the normative sense of truth which involves a becoming that is humanizing and harmonious between private entities and the context that covers them. On the other hand, it is a major challenge for every truth reached in a particular field to come to be regarded as also useful in its generality. Such a coincidence requires, however, the criterion of experience - which also has its motives because, as already stated, reason and reasoning are not ends in themselves but they point to that mo ment of pacification and harmony between the subjective and objective dimensions that can only emerge from experience as understood not only in its historical, social, cultural, instrumental sense, but also its existential one. Nevertheless, it must be acknowledged that if the a priori coincidence of truth and utility is taken as an absolute criterion for the legitimacy of both, the risk is run of abandoning every serious initiative of human progress that cannot yet be tried out in its generality. But as human beings in the midst of the world are still imperfect and in a state that by itself alone justifies the existence of education, this existing generality itself cannot also constitute a final and exclusive representative of the criterion of utility. This is because that which configures itself as useful in its current state is not necessarily clad with the meaning of that utility which, allied to the search for truth which presupposes a pacified reality, can only be grasped from the normative point of view of human formation.

Thus, the ends of "learning to know" and "learning to do" are not divorced from the goal of "learning to live together", to the extent that the normative dimensions of the search for truth and utility are also lin ked to the normat ive dimension of ethics. Thus, only in the sense of what is useful and true for developing and perfecting human beings in the world are knowledge and technology justified. Knowledge is ethical and ethics is also wise inasmuch as these principles are not always trivial and self-evident in all circumstances.

From the above it necessarily follows that truth as an axio logical aspect of the activity of knowing, is expressed as a normative condition not only of the apprehension of that state of things existing in a given situation but also as a result 
of an effort that, by presenting itself as the "knowledge" of something, makes it viable for the possibility of this something to be constituted in the widest possible good that can be at the service of potential beneficiaries. This is how, for example, more accurate knowledge of the nature of cancer, although it is processed by technicians and scientists in the "coldest" laboratory conditions, finds its greatest legitimacy in the benefit that it will provide to many who may come to be struck by this disease. In this case, the truth of the knowledge of a specific state of things finds its full justification in the greater context of its possible beneficiaries. This is also how, in this case, truth and utility are harmonized as intrinsic and incontestable attributes of knowledge, although there may certainly be cases, such as in nuclear energy, for example, in which the absence of conflict between the criteria of truth and utility will not always be assured because, very often, in the name of the noble justification of having access to nuclear technology to improve civilian life, efforts are made to produce military technology.

Therefore, even if it is admitted that the limited perception of a problem may, in this restricted context, be considered useful and/or true, it must be borne in mind that, even in a particular situation, there are many aspects that need to be considered by a reasoning that craves the connotation of truth. Thus, truth and utility are also associated with the principle of reasonability, which is no longer solely of the nature of knowing, but, main ly of the nature of thinking.

Thus, as a partial synthesis of what has been presented to this point, the principle of equality is understood as associated with acknowledging the dignity of all particular subjects before whom every human being is found to be a point of expressing a wide network of interdependence; the principles of truth and utility are identified as regents of the nature of cognitive activity understood in the condition of benefitting life and human beings, and; the principle of reasonability as something that is associated with and illuminates the very criteria of utility and truth.

Reasonability, therefore, is not the assured result of a reasoning which discriminates what an object supposedly is, but rather deals with that dimension which is characterized by a dialogue "without a sound of myself with myself"[11]. This same author[11] suggests the hypothes is that a possible condition for evil to prosper or to become banal is the absence of reflection by the subjects. For this reason, in the book in which she narrates and analyzes the trial of a Nazi officer by an Israeli court[12], she was taken aback because she expected to find a monster, one that would be revealed as the author of numerous atrocities. Instead, to the surprise of many, in the place of a monster there was just an ordinary man whose mind was characterized by the stubborn inability to reflect. He was someone who was prone to clichés and phrases, unable to analyze anything save by the narrow perspective of the words of effect. That being, according to Arendt's analysis, was incapable of exercising thinking as an activity characterized by the inner duality of reflecting; therefore, it remained to him to represent and express everything through ready-made phrases and the repertoire of the ready and automatic responses that he carried with him. Thus, although she did not claim that the cultivation of the capacity of reflection might influence the practice of good, Arendt recognized that at least its non-exercise could contribute significantly to the practice of evil.

According to the above, it is more than admissible to assume that there are several situations in which the principles of truth and utility are not self-evident, but need to be illuminated by the reasonability arising from reflection. Thus, for example, by means of reflection, someone can come to reach the signification that will help him/her to decide on the utility of enhancing what they can do with this or that skill for their own good and for the good of others alongside whom they live and even for the good of people they do not know and will never know. By reflecting, one may find the most appropriate or most significant means to overcome social, cultural, economic or political obstacles that prevent the establishment of genuine human connections in social and interpersonal relationships. Thus, although items of reasoning that arise from reflection may be not of the same nature as those that come from cognition and their being matched to utility, it is they which, nevertheless, confer meaning and direction on the action and way of being in the world. Through thinking, the value of things and events can be weighed up. Thinking, however, also demands the conjunction of formation so that it consists of something that is genuinely proper and appropriate.

Despite what has just been said, there is no guarantee that thinking and the principle of reasonability cannot be distorted and channeled to ends other than perfecting benefiting human beings, society and the ecosystem. What is not a novelty is the understanding that thinking can also be seen as being imp risoned by instrumental princip les that are completely blind as to their human, social and natural repercussions. Horkheimer and Adorno, for example, long ago identified the dimension of domination inscribed on the kernel of reason, fully demonstrating how it can become totalitarian. It is here, therefore, there is a need for reflection itself also to be inspired by the principle of equality derived from the understanding of the interconnection established between human beings and non-humans. It would be a huge discussion - outside the scope of this article - to determine if the admission of the princip le of equality is or is not derived from reasonability. In this respect, Kant[13] long ago took the position that reason alone would be powerless to prove the legitimacy of such a principle; however, on taking a position in favor of human freedom, Kant[14] had recognized that only the sense of practical duty that drives one to action can claim, though it does not prove it, human freedom. Therefore, vis-à-vis this principle, reasonability would consist of obedience to the idea that the mode of acting legitimately is one, the principle of which can be accepted by all. Only in this way could Kant make the principles of equality and reasonability integrate.

Despite all the sophistication of the Kantian argument, nothing proves reason to be the only source, albeit indirectly, 
of the admission of the leg itimacy of equality; Röhr[15], for example, considers that the admission of principles that can hardly be legitimated only by rational instance and personal commitment to them can only be welcomed by means of intuition, it being intuition which would directly communicate the truth of these, without one being able to prove them rationally. However, although it is difficult to identify the origin of the principle of equality, nothing prevents recognizing its importance as an element of reflection that inspires, to the extent that the admission of the interconnection between all beings, with the consequent recognition of the dignity of each one of them, ends up by fostering reflection in order to establish for themselves legitimate parameters like the one that Kant acceded to on enunciating the categorical imperative. Therefore, what is thus observed is a circularity and interconnection among the guiding principles of equality, truth, ut ility and reasonability, which are taken up as normative dimensions of formation.

In addition to these aspects and principles, another normative dimension to be highlighted as to forming humans is with regard to the exercise of introspection. For some, this ability or skill would be a simple outcome of directing reflection to within oneself. Although it is not possible to deny the fact that the inner dialogue of which Hannah Arendt speaks, establishes itself in introspection as a part of the effort of reflecting that seeks to achieve a full signification for the subject, on the other hand, this inner activity is also expressed as a space of experience and contemplation. Despite the fact that experience and contemplation are not attributes or activities that are restricted to the inner ambience but are also exercised with regard to exteriority, the aspect thrown into relief here conceives of introspection as being that articulation between reflection, experience and contemplation directed to interiority and not external space. Thus, although the nature of this triad does not originate from nor is exclusive to internal space, it is necessary to emphasize that its jurisdiction when being exercised in one these areas is not a sign of guaranteeing its success in the other. For instance, scientists, philosophers or poets who articulate their experiences, reflections and contemplation in relation to social, cultural, economic, political and interpersonal aspects, do not necessarily find themselves familiar with and prompted to exercise the same mastery in that which concerns their interior. Thus, they may be very competent, accurate and insightful as to what occurs in the external ambience, but are unable, for example, to understand and deal satisfactorily with the emergence of a passion or other affective aspect, which is because their attention and insight cannot be developed to fathom the internal objects with precision. However, without the exercise and appropriation of reflection, experience and contemplation, jointly exercised with respect to the phenomena of the human interior, that end cannot be developed that Delors Report referred to as "learning to be"[9].

When life is lived with wisdom, the tendency is to realize that indeed there is no separation between introspection and action in the world. By means of self-reflection, i.e., by the exercise of inner dialogue, mental and behavioral habits, feelings and emotions can become progressively the object of reasonability. Without self-pity and inclemency, it is possible that individuals may turn their limits, weaknesses, fears, potentialities and virtues into something familiar by reflecting on them and moving on to calling each of their preponderant attitudes by their due name, thus in fact reaching the point of what one knows of them and discerns about them is their meaning, and not just that of living life as their hostage. By means of this minutely detailed and frequent internal examination, it becomes possible for someone to contemplate serenely his/her mental attitudes and habits, by untangling himself/herself from the standardization and repetition to which he/she has for long undergone. Finally, through experience, it will become possible, gradually, to act in accordance with the principles of one's own self-reflection and contemplation; and, although this coherence may not be attained immediately, what will gradually come about is the clear perception of the aspects that resist being integrated and require further examination, reflection or acceptance in order that one might come to accept oneself as one is and indeed take charge of how one directs oneself in a way that is fully lucid, comprehensible and coherent.

On the other hand, through introspection exercised by self-reflection, contemplation and experience, everyone will be able to recognize their constant incompleteness, by becoming intimately familiar with their thoughts, feelings and attitudes to the point of easily recognizing them in themselves and in others. This will provide personal enrichment in the sense of developing one's comprehension, tolerance and patience toward others. Thus, self-understandi ng tends to be converted progressively into comprehension and acceptance of alterity, which implies, in turn, behavior that is wiser and familiar with the differences already known about and those that may arise.

With progressive but always unfinished achievement in this field, the particular subject will tend to feel less divided; will recognize, with increasing clarity that many of the obstacles, threats and oppositions, which he/she once used to locate in exteriority, were greatly deformed by his/her own projections, ingrained mental habits and because of the lack of intimacy with himself/herself. Thus, many of the stubborn oppositions such as "me-world", "subject-object", begin to become more fragile, which enables the individual subject to experiment with a gradual sense of greater wholeness and integrity - thus there arises the idea of a progressive unification with oneself or an individuation, understood as the process of a continuous overcoming of the various interior divisions, which enables many of the oppositions hitherto considered as a conflict to become dissipated. On the other hand, the progressive realization of individuation acts in concert with the strengthening of the princip le of equality to the extent that the individual, along the course of his/her own life, may recognize in the other the same possibility of pacification and unification with himself/herself. 
However, all the normative princip les so far analyzed only become thinkable and realizable in educational terms and only acquire their raison d'être when they are taken on board under the assumption of the irreducible freedom of the human being. Thus, there is no contradiction between taking on this principle and: a) the admission of equality between people; b) the acceptance of the axiological principle of truth as a quest that is defined by contextual situations; c) the recognition that the best way to employ the possible personal skills is in a way that may simultaneously promote oneself and benefit others, based on the consent of the very interconnectedness of life in general. For the recognition of all these aspects, however, the use of reason and introspecti on will always be necessary in such a way that all these principles may be mutually inter-related with each other.

There is however a fundamental feature in the principle of freedom that sets it apart from all others and is necessarily based on the singularity of another human being and on his/her irreducible difference. This is why education will always be a science and a practice that is never completely predictable. Neither does this mean that this is totally random and not at all predictable. No one who knows the psychology of human develop ment reasonably well will harbour a doubt that a child whose crucial experiences of socialization have been scarred by rejection willvery likely, unless there should be a radical change of course, develop depression or aggress ive behavior patterns, deep insecurity and dependency. This attests to a certain degree of predictability, but without ever being able to fully define the destiny of a human being. This is also the reason why education can never provide a complete guarantee of its results about which some bureaucrats, politicians, economists and practitioners of education itself dream. Accepting this is to recognize the bottomless and free nature of the human being, without denying, however, several conditioning components, but never ones that form a fixed total.

Human freedom, at the same time as its being one of the aspects most accepted by common sense, is nonetheless also a great mystery in its depth. Human acts that transcend humanity cannot be explained but rather it is only by means of the recourse to freedom that they can become humanly comprehensible. An example is the act of renouncing one's own life for the sake of others or the attitude of assuming completely and responsibly the total consequences of one's actions. It is therefore not without reas on that figures such as Socrates, Jesus of Nazareth and some others who historically became emblematic, have been converted into paradigms for humans or into a sign of adoration, as if, in the latter case, they had crossed an imaginary line that would separate them from the common place of mortals.

Attitudes like these, therefore, rather than being exp lained, can only be welcomed when one has in mind the idea of human freedom. On the other hand, however, the result is that is also almost always difficult to explain the reasons that move and moved the great dictators, despots and those with much blood on their hands whether they be from the past or present. When one recalls, for example, that many high-ranking Nazi representatives, and also those who were the so-styled "people's representatives" in the Stalinist regime, or the various "dictatorships of the proletariat" that historically existed and still exist, were lovers of the arts or of sophisticated intellectual debates, one comes to the conclusion that intellectual, cognitive development and even that of sociability do not necessarily guarantee a way of living that is authentically human. Human freedom also emerges here as a limit to the explanation of the coming to be of each individual and also humanity in general.

Thus, without discarding the idea of a certain predictability and, therefore, of a certain condition to prepare the way of human beings in a manner worthy of and appropriate to the very regulative idea of what these should be, this task will always have a degree of uncertainty and inexactitude that does not derive from any intrinsic fault of educating, but results from the very nature of the being on whom education is targeted[16].

Despite the nature of human freedom not being something that can be eliminated and its being imponderable, education cannot take place as such unless it has something to do with a presupposition and a goal. The principles of equality, truth, utility, reasonability, introspection and individuation can only count as such and become really effective to the extent that they come to be taken on in a resolute and free way by human beings. This means that the normative character of education, as it is discussed, only updates itself when it is taken on freely and personally by particular subjects, i.e. when all that was appropriated by them comes to have a meaning and its own nature in each unique being. Only when this internal realization is achieved may in fact it be recognized that the goal of education has been achieved. It should always be stressed, however, that such an achievement will always be dependent on the contribution, participation and volition of the human being hims elf/herself in whose name all education is structured.

So, to make it clearer what is stated here, the educational realization of a particular being will provide his/her acceptance by their free will, without coercion, of the principle of equality between all human beings. Similarly, in the subjective exercise of a reasoning which may not simply designate what something is, but which is also deepened equally into the apprehension of what it should be - but without exercising violence on the nature of the thing itself that is the object of the thought, thus enabling at the same time the match between the thinker and that which is thought - the educated being seeks the truth in a way that, by its very nature, can only be fully updated in a state of freedom of the human being. Similarly, the exercise of all the appropriate skills and capabilities that have been made one's own in such a way that they are expressed as a personal realization and, at the same time, as a utility to others, is something that cannot be unravelled in its amplitude except by the free exercise of the capacities of each unique being. Similarly, a person can live his/her whole life without ever taking introspection seriously. In this case, possibly personal realizations will possibly almost always be divorced from each other, or 
without the individual noticing or constructing internally a sense of how they articulate with each other. However, this mo ment, or rather, this activity of the spirit, by its very nature, cannot exist if the subject freely and by himself does not undertake doing so. This also occurs likewise with individuation without self-examination and self-acceptance of oneself, the human being does not progress along the course of that gradual unification of his/her divisions, which requires, as a basic premise, the free acknowledgement of oneself and the suppression of violence to oneself, no matter to what degree this may be.

Due, therefore, to freedom interpenetrating all the other principles mentioned, education will never be that exact or completely predictable science of which so many planners and bureaucrats dream. On the other hand, however, since the axiological value of such principles have been admitted, no social, political or econo mic realization that is guided by normative human ideals may forego education. And although certainly the latter is far from being the condition and cause of all social, political, cultural and economic phenomena, nor indeed may it set out to be so, education cannot derive its nature simply from the realizations or the influence of one of these fields in particular or from articulating them with each other. This is why, in accordance with such an understanding, it is a complete contradiction of education itself to seek to determine it (which does not mean denying the fact that some theories influence and make contributions to education) based exclusively on theories that do not have it as their main object.

Therefore this is why it is important to understand education as having a normative sense of humanization which springs from its own constitution as a field of research and practice. When this does not occur, and education is converted into the appendix of other sciences or theories developed outside the ambit of education, the very practical repercussions on the educational process tend to be objectified in a way that would contradict its very concept. It is for this reason that there emerged in the past, remain in some way present and may occur in the future, within the field of education itself or outside it, slogans which gain strength at every onslaught of fashion, but do not always arise from eminently educational issues, such as: "Education for social revolution," "Education for economic development", "Education for Citizenship", "Education for competence", etc.

Thus, to take up once more the principle of the argument set out so far, the conception of education as a formative theory and practice of human ity covers not only a description but equally a normative dimension of the human being. This normalization, however, is not directed at content, but at principles, which also only find their complete legitimacy in the ambit and process of the formation itself. Thus, the principles of equality, truth, utility, reas onability, introspecti on, individuation and freedom, are not susceptible to complete and exhaustive proof a priori, but depend on and demand the conjunction of experience, a unique process by which the particular being may come to appropriate these principles for himself/herself, experiencing them, conseque ntly, in an authentically singular way.

\section{Contribution of Buddhism to the Understanding of Human Formation}

In general it can be said that the main purpose of Buddhism is to promote an experiential understanding of the condition of beings and an appropriate understanding of the path to overcoming suffering and its causes with a view to achieving well-being for oneself and others. From what is seen, therefore, the Buddhist tradition also involves a descriptive dimension and a normative one. Just as in the Western understanding of education, however, such a normative does not refer to contents or external means which particular subjects have to obey or achieve.

The normative character of Buddhism, if one may deem such a dimension in this way, consists of the progressive dissolution of the basic ignorance of beings. For this tradition, the fundamental nature of all beings remains in the midst of innumerable forms of ignorance, in a complete, unaltered and constant way. The teachings of the various Buddhist and non-Buddhist schools on this nature are countless, in the same that the practices and the masters that embody and uphold them are many.

The latter always affirm the pure, compassionate, loving and equaniminous character of this fundamental nature of all beings. It will not be possible within this article, to pinpoint or uncover such a nature, since it is not something that is subject to being objectified or conceptualized, and this can be, at most, partially and indirectly recognized by its expression in someone's life, or directly, in one's own life. In this regard, it must be recognized that intellectual assertion is only the expression of a thought or point of view, and cannot, in any way, replace living authentically through what supposedly the discourse expresses and which can be manifested with coherence and harmony between the dimensions of the mind and one's thoughts; of the feelings, emotions and one's energy; and, of the body and one's movements and behavior. Therefore, the possible Buddhist contribution to education must occur in these three areas, and not just in one of them.

To facilitate understanding and permit comparison of the elements belonging to the Buddhist tradition with the principles set out in the first part of this text, a presentation will be made of the relevant aspects of this tradition to the current discussion by way of its translation into these principles, with the evident concern of remaining faithful to the two fields in question.

With regard to the princip le of equality, the first Buddhist observation is not optimistic and refers to the universal suffering of human beings and non-humans. This understan ding reached by the Buddha Shakyamuni before reaching his complete liberation was the main reason for moving him on his spiritual journey of self-discovery. Buddha Shakyamuni discovered that suffering feeds on causalities arising from 
the ignorance of beings as to their intrinsic nature; however, should they be able to recognize such a nature and to be at rest with it in a stable way, they could overcome their mistakes and remove the causes of suffering.

According to this understanding, the affirmation of the universality of suffering does not constitute a normative dimension, but rather a diagnosis of the condition of human beings in general. By recognizing the depth of the origin of suffering, the tendency of Buddhist teachings is to nurture a sense of compassion for beings, to understand the condition of equality between someone who reflects on this, and all other beings. In the words of the Dalai Lama, this comprehe nsion appears as the basis of ethical comprehension and action taking, which need not be associated with any creed or tradition, but can fully be the basis of a lay ethics, according to which everyone "has the same right to happiness and being freed from suffering"[17]. Thus the act of recognizing, welcoming and contemplating on the condition of suffering of all beings and their desire for happiness fosters the development of the sense of equality and the emergence of a shared feeling, compassion.

Besides the aspect of suffering and its causes, the principle of equality is also expressed by recognizing the broad, open and equananimous nature of all beings. To experiment with it, however, it is necessary to dissolve the basic ignorance through which beings erroneously identify themselves.

According to various Buddhist traditions, when the understanding of this dual aspect of the principle of equality the universality of suffering and the constant presence of the primordial nature of all beings - is fully understood and stabilized, then genuine compassion without sentimentality for all beings naturally arises. Just as naturally, without any effort whatsoever, anyone can be moved by a friend or relative who is suffering, or can rejoice in their success or good fortune, and in the same way, personal identification experienced with the universal condition of beings to experience suffering or happiness is the assumption accordi ng to which, in line with Buddhist teaching, a progressively equananimous and deep compassion for all can be nurtured. Thus, compassion is the true result of the realization of the principle of equality in the Buddhist tradition.

The second normative principle mentioned above is the dimension of truth. The theme of truth is of great complexity in all philosophical traditions and, in Buddhism, th is is not an exception. The Buddhist philosophy of every school emphasizes ontological and epistemo logical reflection, to the extent that, for Buddhism, the discussion about the nature of reality has always been linked to the broader aspect of the nature of the mind.

In general, most schools of Buddhist philosophy recognize that there are two truths - an absolute truth and a relative truth[18]. There are also variations in the understanding of the meanings of these truths from school to school. What are adopted here, however, are the meanings of the relative and absolute truths as drawn up and propagated by the Mahayana school of thought ${ }^{1}$, called the Middle Way or Madhyamika or Madhyamaka ${ }^{2}$ school whose founder and one of its greatest exponents was the spiritual master and scholar Nagarjuna $^{3}$ In Buddhism, the point of the comprehension of absolute and relative reality is not a theme that is only of philosophical importance. Instead, it is about seeking to achieve this comprehension and stabilizing it in life in order to see the world and to relate oneself to beings and objects. By understanding absolute nature and its ever-present inspiration in personal and social life, Buddhism accepts that beings can finally free themselves from the causes of suffering.

To understand what the Madhyamika school designates as relative truth, one must recognize that everyday life takes place amid a conventional world defined according to the duality of subject-object. Everyone accepts without question the independent reality of the world of things and beings around one. Science itself is a sophisticated creation that consists of demonstrating unequivocally the nature and the properties of things and phenomena from an essentially objective point of view, namely, in a way that is not restricted to mere opinion or preference. In th is context, there is relative truth. This is, therefore, referred to a conventional world.

In Kant and also in the phenomenology of Merleau-Ponty[19], there are elements that throw light on the understanding of knowledge of what is, or is not, real necessarily depends on the very human constitution or of the structural mode of the subjects relating to the world. Thus, for example, the fact that human beings can visualize and understand the arrangement of things in space or order them along a time continuum, or even their appreciating and interacting with the world from the characteristics intrinsic to their sensoriality and mental structure, all this points to the fact that a human being does not relate himself/herself to nor apprehends the world as it supposedly is in itself, but in accordance with schemata, properties and characteristics that are intrinsic to him/her; and although it is possible, even in this context, to operate the distinction between right and wrong and between truth and falsehood, such a distinction will always be determined by the structural and peculiar manner which defines the nature of the subjects. Thus, it is perfectly possible for the modern man to affirm that that means of transport that floats on the water and moves according to the direction imposed on it by its rudder is a ship and not a plane. To affirm the contrary would obviously be something false and contrary to the truth clearly ad mitted by all. However, it does not take much reflection to discern that such a truth is relative to human experience and possible in certain historical periods and cultural contexts; for the indigenous pre-Columbian Indians this understanding was not at all configured as a truth.

In the example presented, therefore, the recognition, description and enunciation of the object as a ship not only alludes explicitly to its nature, but also implicitly makes reference to the human experience of the subject or the subjects who recognize it as such. Thus, the emergence of the appearance of the object is simultaneous and inseparable from the internal activation of a subject who enunciates it. 
This phenomenon is, for some Buddhist schools, deemed as co-emergence, insofar as the object and the subject emerge inseparably and simultaneously. The ship, in this case, appears as an object placed in space, a three-dimensional one, because this is the way humans recognize things and the world around them. If, on the contrary, human subjects had the intrinsic disposition of apprehension in at least one other possible dimension, the ship would certainly not loom into view in the way they are accustomed to seeing it. Similarly, the recognition of the object as a ship is made possible by basing their common experience ordered according to a temporal continuum; only by means of immediate access to this anchoring of the experience in time, can subjects manage to recognize the object and to apprehend the movement that it performs. Equally, the size, colors, the idea of mass, the ratio of the size of the vessel in relation to other objects and contents of ordinary social experience are perceived in accordance with the sensorial characteristics that enable the human being to interact with the world. Thus, the truth that emerges from the recognition of this object as a ship is necessarily something relative to the structure and the circumstances of the way of being in the world. It is therefore a relative truth.

Still in the Buddhist sense, one may add that the phenomenon in question (the ship) is a relative truth given that it depends on causes and conditions. This means that the phenomenon of a ship cannot arise without the ores supplied by the land, without the technology of engineering, chemistry, teleco mmunications, and therefore it cannot exist without universities and research centers that generate this knowledge, besides its not being able to exist without the interaction between peoples, whether because of travel or trade. So, in a single ship, what are present are the contributions of universities, miners, engineers, chemists, dock workers, etc. Thus, the ship does not have an independent existence, but arises only as a result of the conjunction of several causes and conditions. Thus, the very material existence of the ship is related to these different dimensions and, therefore, has a relative nature.

This analysis of relative truth, for Buddhism, does not apply only to material objects, but also to feelings, perceptions, thoughts, abstract formulations and the very human "I"[18]. Thus, the human sensation of heat or cold is totally relative, in the sense that it depends on the condition of being a mammal and human being and also on personal habits. A temperature of $15^{\circ} \mathrm{C}$ can be cold for one individual and not be so for another only due to the habit of living, or not living, for many years in a cold place. However, a temperature of $0^{\circ} \mathrm{C}$ or $-10^{\circ} \mathrm{C}$ is always cold for every human being, to the extent that, at this level, no human body manages to produce enough heat to keep itself alive, without coats, for a long period. However, this feeling is relative to beings such as humans, whose organic response to low temperatures has these specific characteristics. The same occurs with physical pain. Although there are different thresholds from person to person, there are unmistakable levels of physical pain for all human beings, once more excepting, however, that it is a relative sense. If one applies the same reasoning to the sphere of thought, it will be seen how the degree of relativity becomes even greater when it is perceived in the ambit of the humanities, for example, despite all the conceptual rigor, as there are a large variety theories about any one and the same phenomenon. This does not mean to say that they are completely arbitrary, but such a phenomenon indicates that, according to the diversity of forms in which subjects put themselves in the world and the distinct relationships they experience with different environments, people, things and beings in general, the very way to reflect and systematize the results of this reflection is diversified.

Thus, on taking an example from economics and sociology, the subject who conceives the preponderant social and economic relations as a capitalist system sees the world through different eyes from somebody else who deems it as a free enterprise system. The way that the various concepts are interleaved and produce theories varies in both cases. It could be argued that the conceptual architectures of both theories reflect different forms of vision and situation in the world, despite the possible similarities that may exist. In the case of theoretical traditions that are even more distinct from each other than those mentioned, the way of seeing and experiencing the world by its advocates will be mo re diverse. Thus thought is an expression of a reality that is internal and external to the mind itself; internal relativity necessarily arises from the fact that every piece of reasoning is dependent on others, i.e., no concept or reasoning exists by itself, but is the result of the convergence and interleaving of several others; on the other hand, every piece of reasoning or thought relates to the way of being and acting in the world of whoever enunciates it. Thus, neither does thought have an independent existence; it is not self-constituted and, therefore, also possesses a relative nature.

As to the idea of "I", the various Buddhist schools and traditions make the same reflection. Even though a human body may exist, ordinary experience demonstrates that the identification of individuals is not limited to that because, otherwise, a corpse would be a human being. On the other hand, the body undergoes numerous changes throughout life, there being birth and death of cells throughout the organism. This being so, one and the same particular entity is and is not, in bodily terms, the same being all its life. On the other hand, particular subjects experience fluctuating emotional states, although they do not exactly identify themselves with their emotions. Someone may be calm in a given situation and, depending on some event, be stricken by a passionate anger, and, despite presenting himself/herself as being very different in both conditions, continue to refer to hims elf/herself as a being endowed with an intrinsic identity. Thus, emotions are also unreliable as indicators for determining the identity of a human being. As to the dimension of the mind, the human being also develops spiritual activities, for which thinking is indispensable. These, however, come and go, loom up, dis appear, and cease at certain stages of sleep. On referring to this unknown 
dimension of the origin of thought, Hannah Arendt[11] alludes to a "nowhere" as a pre requisite for man ifesting one's own thinking, as if it were a condition or negative dimension of all mental phenomenon to the orig in of the positivity of thinking. Thus, neither in thoughts can an intrinsic existence be found. In summary, corporeality, emotions and thoughts do not enjoy an intrinsic existence, and none of them on their own can define the nature of the "I". For this reason, the fact of our being able to view such elements but also of our recognizing the insufficiency of them all as to what constitutes the "I" is not an intrinsic defect, but reveals, as Varela, Thompson and Rosh[20] have stated that man's anxiety and habitual disposition are inclined to reduce him to a defined identity.

Thus, according to the preceding reflection, Buddhism also recognizes the relative nature of personal identity, of the self. Therefore, all that has been discussed so far points only to the aspect of relative truth. Where therefore might one find the aspect of absolute truth? If it is ad mitted that all duality between subject and object, whatever they may be, means a relative truth, it is concluded that the absolute or ultimate truth is not something that can be found in this way; it can be understood conceptually, but is not itself, this conceptualization. Absolute truth can also be experienced by non-dual perception but it itself is not restricted to experience. According to the Dalai Lama[18], absolute truth can be experienced, but not limited to such an experience, in a non-dual experience i.e., a condition that transcends the separation between subject and object.

Thus, absolute truth is something that cannot be grasped independently of experience or the condition of the observer himself/herself. This is not about the supposed existence of two realities. However, it refers more properly to a certain kind of insight of the experience in the ambit of relativity itself. Thus, the same phenomenon can be "perceived" or experienced in a relative or absolute way depending on the connection established with it by who ms oever underwent the experience. If such an experience is limited to the phenomenal aspect, i.e., the distinction between phenomena and between these and the subject, what one has is the ambit of relative truth. When experience, however, achieves what constitutes, underpins and from which emerge the phenomena themselves, that is, the emptiness that Buddhism speaks of, then that is about the ambit of absolute truth[20].

Thus, absolute truth is the very condition, without conditions, of the emergence of phenomena; the dimension, without dimension, of the emergence of subject and object; the vacuity of phenomena that is also expressed in the phenomena thems elves. Therefore, emerging, stabilizing and withering away are aspects of a relative nature, which, however, is sustained on absolute nature which is not born, which does not stabilize itself nor does it destabilize itself nor die.

For what, however, is such a distinction made? In fact, Buddhism does not intend to translate this understanding into a fundamental ontology. The basic aspect does not consist of undertaking a minute analysis with the aim of finding vacuity or ultimate reality in itself - indeed, this would be something that in itself would be contradictory and impossible. Ultimate nature is not a phenomenon that is present as a given fact to a specific mind. It is the whole and the condition of the experiences but not the phenomena taken as distinct entities. Thus, there is only relative truth because there is absolute truth and this is only capable of being comprehended by means of its being recognized in the very amb it of phenomena.

Thus, emptiness, i.e. absolute nature, is not an objective to be pursued in itself. This is not about finding something else beyond all phenomena and experiences, but is rather about recognizing in phenomena and experiences, in all their relative dimensions, the absolute nature of everything. A complete clarification of the nature of this experience thus implies the transcendence of the attitude of intending to grab at or to settle on anything, or on oneself. For this reason, any attitude or inner disposition towards craving or being averse to some phenomenon, as well as self-absorption, are considered by Buddhism as the fruit of fundamental ignorance, that is, the incomprehension of insubstantial nature, which at the same time is relative and absolute, of any phenomenon. For this reason, the main motive for understanding and stabilizing absolute truth is a goal of selfless and compassionate action in the midst of the world and beings, with a view to the well-being of them all, which are also the expression of absolute truth; and the formative aspect of the Buddhist tradition consists of this beyond the purely negative aspect of the absence of reality in phenomena. For this reason, as in the warning given by the Dalai Lama[18], vacuity does not interest us in itself; all that is important to us is to recognize that phenomena are empty in the sense that they do not enjoy an intrinsic nature, and it is such an understanding that can help us face up to and overcome our afflictive emotions by recognizing that phenomena are not in themselves what our afflictive emotional states (anger, aversion, desire, etc.) state to us that they are.

As a result of the above, according to Buddhism, the normative principle of truth in its double dimension is directly associated with the compassionate dimension mentioned earlier. For its part, insofar as this dimension refers to overcoming a state of self-centered ignorance, the realization of this truth implies modifications in what motivates us and in ways of being and acting in the world, and it is here that the aspect of the formative dimension comes in, which was mentioned previously as individuation, in relation to education.

For Buddhism, the realization of vacuity in relation to ones elf, far fro m imp lying a nihilistic perspective, represents the freedo mto be and act in the world in a way that is open to every experience, without the customary and ingrained self-centeredness[21]. The freedom to recognize that the nature of each person is not limited to the roles, preferences, patterns and bodily, mental and emotional habits which have been fed for a very long time is what provides the progressive personal openness to previously unknown 
dimensions of one's own particular being. A natural feeling of disinterested compassion and one that has no self-reference can then begin to be established. On the other hand, insofar as flexibility and opening to different experiences, no longer pre-formed by personal standards, are established, the pers on naturally starts to live a life with less of an inner split, thus reducing his/her divisions with himself/herself. It can be seen therefore that the Buddhist teaching about the denial of I (in the absence of its intrinsic nature, as explained earlier) is a preparation for the understanding that while the subject clings to a notion of himself/herself, he/she will not be able to perceive genuine and true ways of relating to profoundness and maturity with other beings and contexts. There is no doubt that particular beings will always be interlinked, even although the qualitative nature of these relationships will depend on the state of spirit, openness and comprehension that may develop. Sometimes it will be necessary to make options and choices between one role or another, between one or another identity. The manifestation of spiritual wisdom is not characterized by the specific content of this or that option chosen, but rather by the lucidness and flexibility in the apprehension and acceptance of one's own being in an integral manner, in order to enable the wholeness and harmony between one's own thin king and feeling, between knowledge and affect, between the transcendent and the immanent in the ambit of the very limited identity of each person, so that the particular being may not come to be divided between what he/she does and what he/she wants, between the role and the comprehension that one judges necessary for oneself and for others.

Fro $m$ the above, it als o follows that the formative principle of utility will be structured in an open way that is able to transcend a defined conception of identity. The very sense of identity will be gradually transformed into the vision that it is possible to be useful to others, society and the ecosystem in several ways. To the extent that one may understand and pay attention to the absence of one's own identity that subsists on itself, - that is, to the fact that the absolute truth of the nature of beings in general is empty and insubstantial, and that these arise only as a result of causes and conditions which also in themselves are non- subsistent - there will be no reason why one should employ effort only for oneself, instead of acting with the focus on oneself and on others.

Thus, according to the above, the formative dimension that arises from a Buddhist perspective points to the bringing about of the interrelationship between the principles of absolute and relative truth, of reasonability inspired by such truths, of compassion, of the utility of knowledge that is not self-centered, of self-comprehension shorn of oneself and integrated to oneself at the same time from the standpoint of being and acting in the world in a beneficial way to oneself and to other beings. Consequently, this is not at all about a narcissistic formative ideal. The progressive and never completed overcoming of the various internal divisions that torment the individual, which see to it that he/she is not the non-divided instance to which the concept alludes, blossoms based on the seeds that are already present within him/her, although these seeds are not specific and unique to any particular entity; what alone are suitable are the aspects that can be developed from these seeds, such as, for example, the useful and constructive employ ment skills for the benefit of oneself and others. However, the subtle energy capable of pushing development in this direction is not anyone's property and at the same is common to everyone. Individuation, in this case, manifests itself not as a goal of forming a substantial subject, defined according to a priori properties or characteristics. This is neither a question of proposing nor of bringing about a new fixation around an "I". For Buddhism, which in fact does not use this term, individuation would only be the understanding and overcoming of the afflictive emotions that generate conflicts between the relative dimensions of subjectivity and objectivity. In this case, overcoming this division does not consist of re-establishing of any form of personal synthesis, nor of any new substantial subject emerging but of recognizing that it is each and every time produced from the absolute nature of what is expressed, relatively, in the external sphere and in the internal sphere, or, in other words, of recognizing the inseparability between he who sees and that which is seen, and, consequently, in welcoming and being open to the perennial nature of all that is manifested. In the understanding of Buddhism, as already explained, all humans have this innate ability to dispel their illusions and ignorance and cultivate an attitude of openness towards oneself, others, society and the environment.

\section{Conclusions}

The normative principles of education presented here equality, truth, usefulness, reasonability, introspection, individuation, freedo $\mathrm{m}$ - do not form an exhaustive list of the idea of human formation. There are certain ly other important dimensions to be taken account of within formation, for example, the principle of beauty. The perspective adopted here, however, despite its incompleteness, is based on the assumption that, without these principles, neither is education also exercised according to the normative idea that ought to direct it.

As to the contribution of Buddhism to the idea of formation, though it uses a different language from the classical theories of education in the West, there is no doubt about the convergence of the principles of that tradition with the educational goal that emerges from them. More than mere coincidence, this convergence seems to arise due to the very nature of the object of education, which is the task of formation. Thus, what is fundamental to the environment of education does not seem to be the contribution of one particular theory or tradition, but, principally, clarity on the principles that shape the nature of educating. Without these, the possible contributions fromother theoretical, scientific or spiritual fields may hinder more than bring benefits to the theory and practice of human formation. Thus, the intrinsic 
conviction about what thinking and acting educationally by educators and the scientific and technical field consists of becomes indispensable so that the very dialogue with other traditions, whether or not they are scientific ones, can be undertaken. It is only on this basis that the contributions from other fields and theories can in fact be ones that enrich the core of education conceived as human formation.

Finally, all the formative principles presented here are related to their being appropriated by the individual subject but what have not been mentioned, except indirectly, are the conditions needed from the objective point of view (social, cultural, political, economic ones) such that education may be amply expressed as human formation. It is consequently necessary to emphasize that these aspects are not in any way whatsoever less important than those analyzed here, but on the contrary, it may be safely claimed that a society, culture, and political or economic structure attest as much to their degree of humanity as they express, structure and stimulate the development of those formative principles which have been analyzed here. On the other hand, this article did not set out to analyze such objective conditions so that it might germinate in a substantive way the act of education. However, as can be gathered from all that was analyzed here, without the clear discernment of those fundamental principles one can easily fall into the opposite extreme of the theoretical perspectives that have it that educational problems and solutions lie only in the social, economic, political or cultural spheres, a tendency that gives clear signals of being hegemonic in the current educational landscape, at least in Brazil. This ends up by transferring to the forms of logic operating in these spheres the legitimacy of directing and establishing, in an alienated and extrinsic way, the educational princip les in use, thus reproducing, in the educational field, the lines of force which, from the outside, impinge on that field the negative aspects that the representatives of those spheres supposedly want to overcome.

\section{Notes}

1. The Mahayana, or Great Vehicle, is not only a school of thought, but also a great form or princip le of understanding and practice of Buddhism. It was so considered because it accepts that enlightenment and true compassion are inseparable. The practising mahayana does not wish to seek enlightenment for himself but for the setting free of all beings.

2. The Madhyamika school was called the "Middle Way" because it affirms that there is no objective reality independent of the mind, as well there not being a mind without objective existence. Thus, this schooldenies both the absolutism of the mind as well as that of the world.

3. An eminent Buddhist master and philosopher who was born in the south of India, about the start of the Christian era. $\mathrm{He}$ is acknowledged as a patriarch and common ancestor in the lineage of the masters of different schools of contemporary Buddhism.

\section{REFERENCES}

[1] Jon Kabat-Zinn, “An out-patient program in Behavioral Medicine for chronic pain patients based on the practice of mindfulness meditation: Theoretical considerations and preliminary results”, Pubmed, Gen. Hosp. Psychiatry, vol. 4, no. 1, pp. 33-47, 1982.

[2] Jon Kabat-Zinn, Coming to Our Senses: Healing Ourselves and the World Through Mindfulness. Hyperion, USA, 2005.

[3] Ruth A. Baer, "Mindfulness Training as a Clinical Intervention: a conceptual and empirical review”, Society of Clinical Psychology, Clinical Psychology: Science and Practice, vol. 10, no .2, pp. 125-143, 2003.

[4] Jeanne W. Rothaupt \& Michael M. Morgan, “Counselors’ and Counselor Educators’ Practice of Mindfulness: a qualitative inquiry”, American Counseling Association, Counseling and Values, vol. 52, pp. 40-54, 2007.

[5] Werner Jaeger, Paidéia: A Formação do Homem Grego. Martins Fontes, Brazil, 2001.

[6] M. Horkheimer \& W. Theodor Adorno, Dialética do esclarecimento: fragmentos filosóficos. Zahar, Brazil, 1985.

[7] Herbert Marcuse, A Ideologia da sociedade industrial - o homem unidimensional. Zahar, Brazil, 1979.

[8] Cornelius Castoriadis, As Encruzilhadas do labirinto, III: o mundo fragmentado. Paz e Terra, Brazil, 1992.

[9] Jacques Delors (org.), Educação: um tesouro a descobrir. Relatório para a UNESCO da Comissão Internacional sobre educação para o século XXI. Cortez; MEC: UNESCO, Brazil, 2003.

[10] Herbert Marcuse, Razão e revolução: Hegel e o advento da teoria social. Paz e Terra, Brazil, 1978.

[11] Hannah Arendt, A Vida do Espírito - o pensar, o querer, o julgar. Relume Dumará, Brazil, 2000.

[12] Hannah Arendt, Eichmann em Jerusalém - um relato sobre a banalidade do mal. Companhia das Letras, Brazil, 1999.

[13] Immanuel Kant, Crítica da razão pura. 2 Volumes, Nova Cultural, Brazil, 1987.

[14] Immanuel Kant, Crítica da razão prática. Edições 70, Portugal, 1986.

[15] Ferdinand Röhr, “Intuição e Formação do Educador”, Associação de Educação Católica, Revista de Educação AEC, vol. 29, no. 4/6, pp. 123-140, 2000.

[16] Otto F. Bollnow, Pedagogia e filosofia da existência - um ensaio sobre formas instáveis de educação. Vozes, Brazil, 1974.

[17] XIV Dalai Lama, O Caminho para a liberdade. Record; Nova Era, Brazil, 2003.

[18] XIV Dalai Lama, Dzogchen: a essência do coração da grande perfeição. Gaia, Brazil, 2006.

[19] Maurice Merleau-Ponty, Fenomenologia da percepção. Martins Fontes, Brazil, 1999. 
[20] Francisco J. Varela, Evan Thompson, Eleanor Rosh, A Mente corpórea - ciência cognitiva e experiência humana. Instituto Piaget, Portugal, 2001.
[21] José Policarpo Junior, “A Individualidade - concepção negativa e positiva, segundo o budismo", Quarteto Editora, Ágere: Rev. de Educação e Cultura, vol. 1, no. 7, pp. 20-45, 2004. 